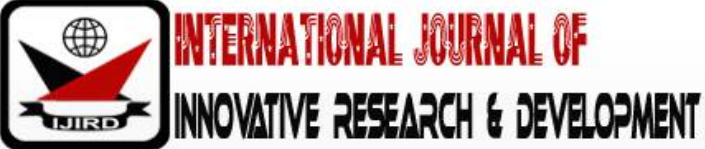

ISSN 2278 - 0211 (Online)

\section{A Review of Psychological Therapy Modalities for Hearing Loss Related Depression}

B. A. Eegunranti
Senior Lecturer, Department of Psychiatry, LAUTECH Teaching Hospital,
College of Health Sciences, Nigeria
A. O. Olaosun
Associate Professor, Department of Otorhinolaryngology,
A. A. Adeosun
Senior Lecturer, Department of ENT, University College Hospital
College of Medicine, University of Ibadan, Oyo State, Nigeria
O. Ogundiran
AATECH Teaching Hospital Osogbo and ENT Department, Coge of Health Sciences, Nigeria
Associate Lecturer, Department of Otorhinolaryngology / Head and Neck Surgery,
A. C. Ogundiran
LAUTECH Teaching Hospital Osogbo and ENT Department, College of Health Sciences, Nigeria
J. Falade
Lecturer, Department of Mental Health, Afe Babalola University, Nigeria
J. E. Tobih
Associate Professor, Department of Otorhinolaryngology,
LAUTECH Teaching Hospital Osogbo and ENT Department, College of Health Sciences, Nigeria

\begin{abstract}
Depression is characterized by low mood, loss of interest in pleasurable activities and reduced energy level. It can either be precipitated or perpetuated by hearing impairment. People with hearing impairment are faced with the risk of rejection from the society, many people prefer to use glasses than to wear hearing aid because of negative societal perspective to hearing aid. People with hearing impairment may have a negative view about the world, paranoid idea about people, pessimistic views, feeling of being different especially when wearing hearing aid. Patients suffering from hearing loss have psychosocial difficulties and depression, the importance of psychological assessment in their management cannot be over emphasized. It is evident that cognitive behavioral therapy can be effective for easing the distress caused by hearing loss. Psychotherapy must be targeted towards improving the negative thought, pessimistic view about life and coping with the stress of wearing hearing aid. Competent mental health counselors managing clients with hearing loss help to focus on the clients' strengths and assets. Strengths-based counseling always focuses on capability, not disability. Individuals with hearing loss learn to reject society's challenges to handicap them through limitations, restrictions, and discrimination.
\end{abstract}

Keywords: Hearing loss, psychotherapy, cognitive behavioural therapy, hearing aid, depression

\section{Introduction}

Depression is a mood disorder that is characterized by major symptoms low mood, loss of interest in pleasurable activities and reduced energy level (World Health Organization, 2017). Hearing impairment can be a precipitating and perpetuation factor for Depression because it can affect social, family, and occupational relationship. The diminished ability to hear and to communicate is frustrating however the strong association between hearing impairment and social decline adds further to the burden on individuals who are hearing impaired (Appollonio, Carabellese, Frattola, Trabuc-chi, 1996).

An Examination Survey of Hearing Impairment Associated With Depression in US Adults between 2005-2010 by $\mathrm{Li}$, Zhang, Hoffman Cotch, Themann and Wilson (2014) found that the prevalence of moderate to severe depression (PHQ9 score, $\geq 10$ ) was $4.9 \%$ for individuals reporting excellent hearing, $7.1 \%$ for those with good hearing, and $11.4 \%$ for participants who reported a little trouble or greater hearing impairment. 
The primary clinical management intervention for people with hearing loss is hearing aids but not all people with some measurable form of hearing loss are candidates for hearing aids (Kochkin, 2009). The people living with the impairment may have ineffective communication and this may be stressful and emotionally disturbing because they can be stigmatized by the society. Furthermore, depression and hearing impairment have been associated with personal, societal, and economic burden (Hogan, O’Loughlin, Miller and Kendig, 2009).

Despite the negative consequences associated with hearing loss, only one out of five people who could benefit from a hearing aid actually wears one (World Health Organization, 2006). People with hearing impairment are faced with the risk of rejection from the society, many people prefer to use glasses than to wear hearing aid. Abby and Heather (2013)reported that majority (80\%) of adults aged 55-74 years who would benefit from a hearing aid, do not use them. Besides, the cost of purchasing and maintaining hearing aid is high for significant proportion of people using hearing aid especially in Africa where may people live on less than $\$ 1$ per day (Cohen-Mansfield and Taylor, 2004).

Based on data from the 1999-2006 cycles of the National Health and Nutritional Examination Surveys (NHANES) in the United States, Chien and Lin (2012) report that one in seven individuals aged 50 years or older with a hearing loss uses a hearing aid. Overall, the prevalence of hearing aid use increases with every age decade from $4.3 \%$ for adults aged 50-59 years, to $22.1 \%$ for adults aged 80 years and older. Chien and Lin (2012) estimate that nearly 23 million adults in the United States have a hearing loss (PTA $25 \mathrm{~dB}$ hearing level or greater in both ears) but do not use hearing aids.

Numerous studies have examined hearing aid usage, including a recent systematic review of studies measuring and reporting hearing aid usage in older adults since 1999 (Perez and Edmonds, 2012). They found there was a lack of consistency and robustness in the way that usage of hearing aids was assessed and categorized. Fifteen different methods were identified for assessing the usage of hearing aids, so it is clear that there is no standard tool for evaluating hearing aid usage. Furthermore, historically, hearing aid ownership and regular use of hearing aids has been found to be low (Upfold and Wilson, 1980) and the numbers of people given a hearing aid who do not wear it/ them ranges from $4.7 \%$ (Hougaard and Ruf, 2011) to 24\% (Hartley, Rochtchina, Newall, Golding and Mitchell, 2010).

In the 1980s, (pre-digital hearing aid era) in a follow up study of 150 people fitted with a hearing aid in Finland, 23\% reported never wearing their hearing aid two years after they had been fitted (Sorri, Luotonen and Laitakari 1984). The reasons given included trouble handling the aid and little opportunity to converse with others. Brooks (1985) also found that reasons given for non-use of hearing aids included difficulty inserting the ear mould, difficulty coping with signals in noise, lack of recognition of hearing loss, advanced age and poor health, and less than ideal matching of the aid to the loss of hearing. It might be expected that nearly three decades later, reasons for non-use of hearing aids might be quite different, especially given the improvements in hearing aids typically available.

Digital hearing aids now offer a number of advantages over analogue hearing aids including increased comfort; digital feedback reduction; digital noise reduction; digital speech enhancement, automatically switching listening programmes, directional microphones, and remote controls, as well as smaller size and open fit design. Benefits of digital hearing aids also include improved sound quality, multiple listening programs for different listening environments, compatibility with remote control options, and flexibility in manipulation of the frequency, compression, and gain (Davis, 2001). As such, audiologists now have greater flexibility in choosing appropriate technology for the needs of older adults.

Despite the improvements in hearing aids, usage is still low and the underuse of hearing aids among older adults is still of significant concern. Hearing aid usage has been found to improve quality of life issues, specifically improving communication in relationships; intimacy and warmth in family relationships; emotional stability; sense of control over life events; perception of mental functioning and physical health (Kochkin, 2012). If a patient does not wear their hearing aid then it could impact on their quality of life as well as others around them, and may also increase their risk of depression and anxiety (Gopinath, Wang, Schneider, Burlutsky, Snowdon, McMahon, Leeder and Mitchell, 2009). In countries where there is access to quality audiological services, it is imperative to resolve why people fail to use their hearing aids (Goulios and Patuzzi, 2008). Identifying factors that affect hearing aid usage is necessary for devising appropriate rehabilitation strategies to ensure greater use of hearing aids.

The majority of literature on the reasons for non-use of hearing aids was published before the introduction of digital hearing aids in the NHS in the UK. Given that digital hearing aids were designed to offer practical and clinical advantages over analogue hearing aids it might therefore be reasonable to expect an increase in the numbers of people wearing their hearing aids over this period. Yet this has not happened. The reasons are not clear as to why some people who need hearing aids and possess them do not use them. Therefore, there is a need to look at the literature over the past decade examining the reasons for non-use of hearing aids. We might also expect a difference in reasons for non-use between gender and age, considering that women report a higher prevalence of daily and regular use of hearing aids (Staehelin, Bertoli, Probst, Schindler, Dratva and Stutz 2011), and Kochkin (1993) found that adults aged 35 to 44 were twice as likely to cite stigma as a reason to reject a hearing aid, compared to adults aged 75 to 84 years old.

\section{Managing Risk Factors for Depression in People with Hearing Impairment Psychologically}

People with hearing impairment may have a negative view about the world, paranoid idea about people, pessimistic views, feeling of being different especially when wearing hearing aid, hopelessness and worthlessness (Abrams, Barnett, Hoth, Schultz, and Kaboli, 2006). Psychotherapy must be targeted towards improving the negative thought, pessimistic view about life and coping with the stress of wearing hearing aid. The therapist may give example people using hearing aid and emphasize the positive effect of it. So that the patient can have positive appraisal of using hearing aid. Psychotherapy involves communication between the therapist and the client, if the client has hearing impairment the therapist will need an interpreter or understand sign language (Cozolino, 2017). Working with an interpreter for the first time require the therapist to set up a time to meet with the interpreter before the opening session 
with the client, He must be acquitted with Deaf culture, the role of interpreters and the protocol of interpretation e.g. the therapist speaking directly to and maintaining eye contact with the client (Romero, 2016). The interpreter must be comfortable and give the therapist feedback around elements of their communication style that present technical difficulties encountered during the therapy (Raval, 1996).

Special techniques of psychotherapy such as psychodrama, anger release work etc. require the interpreter to understand the therapist's expectations. Understanding the point or desired outcome of the work helps the interpreter put things in a context (Izydorczyk, 2011). During each session of psychotherapy, the patient will be allowed to ventilate his mind about his knowledge about risk factors for depression, management, complication and perception about hearing impairment and the uses of hearing aid. Psychological treatment e.g. cognitive behavioral therapy, counseling will be employed to correct the client, thought and behavior.

\section{Types of Psychotherapy}

\subsection{Cognitive and Cognitive - Behavioral Therapies}

There may be hundreds of forms of psychotherapy and a considerable overlap exists among them. Richard (2012), identified the following psychotherapies; Cognitive therapy, Jungian therapy, Adlerian therapy, Existential therapy, Person-centered therapy, Gestalt therapy, Behavioral therapies, Reality therapy, Constructivist therapy and Family therapy.

Cognitive and Cognitive-behavioral models of psychotherapy view psychopathology as the result of faulty thinking (Cognitions) based on illogical beliefs. Various forms of mental illness especially depression results from the powerful influence of these cognitions, for which there is understood to be little or no irrational basis. The patient's unsubstantiated beliefs ("others would be better off if I were dead") are challenged, with more adaptive beliefs implicitly or explicitly suggested and supported. The patient is thereby persuaded to discard irrational perspectives on the world ("no one will want you if you are not perfect") and replace them with more realistic, validated beliefs.

Based largely on social learning theory, these approaches posit that organisms are not just the passive recipients of stimuli that impinge on them but instead interpret and try to make sense out of their worlds. Epictetus in the first century AD, wrote that "People are disturbed not by things, but the view which they take of them" (Ebert, Loosen, Nurcombe and Leckman, 2008).

Cognitive therapists are particularly concerned with the impact of thinking on individuals' personalities. Although cognitive processes are not considered to be the cause of psychological disorders, they are a significant component. In particular, automatic thoughts that individuals may not be aware of can be significant in personality development. Such thoughts are an aspect of the individual's beliefs or cognitive schemas, which are important in understanding how individuals make choices and draw inferences about their lives. Of particular interest in understanding psychological disorders are cognitive distortions; inaccurate ways of thinking that contribute to unhappiness and dissatisfaction in the lives of individuals.

Although several theories of psychotherapy emphasize cognitive aspects of treatment, cognitive therapy is associated with the work of Aaron Beck born in 1921. Originally a practicing psychoanalyst, Beck (2001) observed the verbalizations and free associations of his patients. Surprised that his patients experienced thoughts they were barely aware of and did not report as a part of their free associations, he drew his patients' attention to these thoughts. Appearing quickly and automatically, these thoughts or cognitions were not within the patients' control. Often these automatic thoughts that patients were unaware of were followed by unpleasant feelings that they were very much aware of (Beck, 1991). By asking patients about their current thoughts, Beck was able to identify negative themes, such as defeat or inadequacy, which characterized their view of past, present, and future.

Having been trained as a psychoanalyst, Beck compared his observation of automatic thoughts to Freud's concept of the "preconscious". Beck (1967) was interested in what people said to themselves and the way they monitored themselves, their own internal communication system. From the internal communications within themselves, individuals formed sets of beliefs, an observation reported earlier by Ellis (1962).From these important beliefs, individuals formulated rules or standards for themselves, called schemas, or thought patterns that determine how experiences will be perceived or interpreted. Beck noticed that his patients, particularly those who were depressed, used internal conversations that communicated self-blame and self-criticism. Such patients often predicted failure or disaster for themselves and made negative interpretations where positive ones would have been more appropriate.

From these observations, Beck formulated the concept of a negative cognitive shift, in which individuals ignore much positive information relevant to them and focus instead on negative information about themselves. To do so, patients may distort observations of events by exaggerating negative aspects, looking at things as all black or all white. Comments such as "I never can do anything right," "Life will never treat me well," and "I am hopeless" are examples of statements that are over generalized, exaggerated, and abstract. Beck found such thinking, typical of individuals who are depressed, to be automatic and to occur without awareness. Many of these thoughts developed into beliefs about worthlessness, being unlovable, and so forth. Such beliefs, Beck (1967) hypothesized, was formed at earlier stages in life and became significant cognitive schemas.

Although Beck's early work focused on depression, he applied his concepts of automatic thoughts, distorted beliefs, and cognitive schemas to other disorders. For example, he explained anxiety disorders as dominated by threat of failure or abandonment. From observations of patients and going over transcripts of sessions, Beck identified cognitive schemas that were common to people with different types of emotional disorders and developed strategies for treating them. 
In describing schemas, Beck and Weishaar (1989) noted that schemas develop from personal experience and interaction with others. Some of the schemas are associated with cognitive vulnerability or a predisposition to psychological distress. For example, patients who are depressed may have negative schemas such as "I can't do anything right," "I won't amount to anything," and "Other people are much more adept than I." In this way, cognitive vulnerability can be seen in distorted or negative schemas

\subsection{Cognitive Distortions}

An individual's important beliefs or schemas are subject to cognitive distortion. The thought processes that support schemas may reflect errors in reasoning. Cognitive distortions appear when information processing is inaccurate or ineffective. In his original work with depression, Beck (1967) identified several significant cognitive distortions that can be identified in the thought processes of depressed people.

Freeman (1987) and DeRubeis, Tang, and Beck (2001) have discussed a variety of common cognitive distortions that can be found in different psychological disorders. Nine of these are described here: all-or-nothing thinking, selective abstraction, mind reading, negative prediction, catastrophizing, overgeneralization, labeling and mislabeling, magnification or minimization, and personalization

\subsection{All-or-Nothing Thinking}

This is thinking that something has to be either exactly as we want it otherwise, it is a failure, we are engaging in all-or-nothing, or dichotomous, thinking. An older adult who says, "Unless my communication is $100 \%$ accurate in a meeting, I have failed" is engaging in all-or-nothing thinking. Any attempt to ask a speaker to repeat himself during the meeting, he has seen his communication as unsatisfactory.

\subsection{Selective Abstraction}

Sometimes individuals pick out an idea or fact from an event to support their depressed or negative thinking. For example, an elderly patient who has been communicating well in a gathering and because he could not understand what somebody said to him and did contrary to what was said may make him to focus on an error he has made and dwell on it. Thus, the elderly man has selectively abstracted one event from a series of events to draw negative conclusions and feel depressed.

\subsection{Mind Reading}

This refers to the idea that we know what another person is thinking about us. For example, a man may conclude that his friend does not communicate with him on phone any longer because he has presbyacusis. In fact, the friend may have many reasons, such as other commitments, financial condition and ill-health too.

\subsection{Negative Prediction}

When an individual believes that something bad is going to happen, and there is no evidence to support it, this is a negative prediction. A person may predict that if he attends a social gathering he may sustain injury when there is a fire outbreak in the event hall and other people with good hearing may escape, he may not be able to hear the fire alarm due to his hearing loss even though he has gone to such a social gathering and came home safely. In this case, the inference about calamity, the negative prediction is not supported by any fact.

\subsection{Catastrophizing}

In this cognitive distortion, individuals take one event they are concerned about and exaggerate it so that they become fearful. For example, an individual with hearing loss may think that he may not be able to hear and understand the question in a promotional interview thereby jeopardize his career advancement

\subsection{Overgeneralization}

Making a rule based on a few negative events, individuals distort their thinking through overgeneralization. For example, someone may conclude: "because I suffer from hearing loss, I can communicate and due to this, I am good for nothing". Thus, a negative experience with a few events can be generalized into a rule that can affect future behavior.

\subsection{Labeling and Mislabeling}

A negative view of oneself is created by self-labeling based on some errors or mistakes. A person who has had some awkward incidents with acquaintances might conclude, "I wear a pair of hearing aid before I can communicate effectively, thus I am not a normal human being or I cannot succeed among normal hearing people". In labeling and mislabeling in this way, individuals can create an inaccurate sense of themselves or their identity. Basically, labeling or mislabeling is an example of overgeneralizing to such a degree that one's view of oneself is affected.

\subsection{Magnification or Minimization}

Cognitive distortions can occur when individuals magnify imperfections or minimize good points. They lead to conclusions that support a belief of inferiority and a feeling of depression. An example of magnification is an individual who thought his pastoral ministry has ended because the audiogram interpretation reads bilateral moderately-severe sensorineural hearing loss. In contrast, an example of minimization would be a pastor who has just been confirmed with old age hearing loss through a standardized hearing tests and had a major crusade afterwards and still thinks; "Even 
though I had a good day in today's crusade, it's not good enough. It's not up to my standards." In either magnification or minimization, the pastor is likely to feel depressed.

\subsection{Personalization}

Taking an event that is unrelated to the individual and making it meaningful produces the cognitive distortion of personalization. Examples include "as an individual with hearing loss, it is only when I ask questions that people respond in a low voice. It is only when I am seated at the back that there is always no electricity to power the microphone. If they occur frequently, such cognitive distortions can lead to psychological distress or disorders. Making inferences and drawing conclusions from a behavior are important parts of human functioning. Individuals must monitor what they do and assess the likelihood of outcomes to make plans about their social lives, romantic lives, and careers. When cognitive distortions are frequent, individuals can no longer do this successfully and may experience depression, anxiety, or other disturbances. Cognitive therapists look for cognitive distortions and help their patients understand their mistakes and make changes in their thinking.

\section{Goals of Therapy}

The basic goal of cognitive therapy is to remove biases or distortions in thinking so that individuals may function more effectively. Attention is paid to the way individuals process information, which may maintain feelings and behaviors that are not adaptive. Patients' cognitive distortions are challenged, tested, and discussed to bring about more positive feelings, behaviors, and thinking. To remove biases or distortions in thinking, therapists attend not just to automatic thoughts but also to the cognitive schemas that they represent. Thus, changing cognitive schemas is an important goal of cognitive therapy (Richard, 2012).

Changing cognitive schemas can be done at three different levels (Beck et al., 2004). The most limited type of change is schema reinterpretation. Here an individual recognizes the schema but avoids or works around it. For example, a perfectionistic person might not change the perfectionism, but rather work as an inspector where these traits are valued and reinforced. In schema modification an individual makes some but not total changes in the schema. Beck et al. (2004) give an example of a person with paranoia who makes changes to trust some people in certain situations but continues to be careful in trusting people in general. The highest level of schema change is schematic restructuring. For example, a person with paranoia who became trusting of others would have restructured his significant cognitive schema. Such a person would believe that others would be trustworthy and not likely to attack him. These three levels of schema change provide a way to examine goals in cognitive therapy.

Generally, when establishing goals, cognitive therapists focus on being specific, prioritizing goals, and working collaboratively with clients. The goals may have affective, behavioral, and cognitive components, as seen by this example from Freeman, Pretzer, Fleming, and Simon (1990): Frank, a depressed salesman, initially stated his goal for therapy as, "to become thebest that I can be." When stated in that way, the goal is quite vague and abstract. It also was clearly unmanageable, considering that Frank was so depressed that he could not manage to revise his résumé or do household chores. After considerable discussion, Frank and his therapist agreed on more specific goals including "feel less depressed and anxious, decrease amount of time spent worrying, and actively hunt for a job.

\subsection{Assessment in Cognitive Therapy}

Assessment of client problems is an important procedure in cognitive therapy, both at the beginning of therapy and throughout the entire process so that the therapist may clearly conceptualize and diagnose the client's problems. As assessment proceeds, it focuses not only on the client's specific thoughts, feelings, and behaviors but also on the effectiveness of therapeutic techniques as they affect these thoughts, feelings, and behaviors. Assessment techniques that have been designed include client interviews, self-monitoring, thought sampling, the assessment of beliefs and assumptions, and self-report questionnaires (Beck, Freeman, Davis and Associates 2004; Whisman, 2008).

\subsection{Interviews}

In the initial evaluation, the cognitive therapist may wish to get an overview of a variety of topics while at the same time creating a good working relationship with the client. The topics covered are similar to those assessed by many other therapists and include the presenting problem, a developmental history (including family, school, career, and social relationships), past traumatic experiences, medical and psychiatric history, and client goals. Therapists may use previously developed structured interviews (Beck et al., 2004) or non-structured interviews. Freeman, Pretzer, Fleming, and Simon. (1990) emphasized the importance of getting detailed reports of events.

\subsection{Self-Monitoring}

Another method used to assess client thoughts, emotions, and behaviors outside the therapist's office is selfmonitoring. Basically, clients keep a record of events, feelings, and/ or thoughts. This could be done in a diary, on an audiotape, or by filling out a questionnaire. One of the most common methods is the Dysfunctional Thought Record (DTR) (Beck, Rush, Shaw and Emery, 1979).

\subsection{Thought Sampling}

Another method for obtaining information about cognitions is thought sampling (Blankstein and Segal, 2001). Having a tone sound at a random interval at home and then recording thoughts is one way to get a sample of cognitive patterns. Clients may then record their thoughts in a tape recorder or notebook. 


\subsection{Scales and Questionnaires}

In addition to these techniques, previously developed self-report questionnaires or rating scales can be used to assess irrational beliefs, self-statements, or cognitive distortions (Whisman, 2008). Structured questionnaires have been developed for specific purposes, such as the Beck Depression Inventory (Beck, Ward, Mendelson, Mock, andErbaugh, 1961), the Scale for Suicide Ideation (Beck, Kovacs and Weissman, 1979), the Dysfunctional Attitude Scale (Weissman, 1979), and the Schema Questionnaire (Young and Brown, 1999). Questionnaires such as these are usually brief and can be administered at various points in therapy to monitor progress. For example, the Beck Depression Inventory consists of 21 items, with each containing four choices expressing degrees of sadness, dislike, guilt, crying, worthlessness, and similar items. Each choice is brief, with most being less than eight words long. Additionally, psychological inventories such as the Minnesota Multiphasic Personality Inventory may be used for similar purposes.

\subsection{Modern Approaches of Cognitive and Cognitive-Behavioral Therapies}

Modern cognitive and cognitive-behavioral approaches got their impetus from two converging lines of development. One branch was developed by theorists such as Ellis (1962), the founder of rational-emotive therapy and Beck (1976), the founder of cognitive therapy, began their careers adhering to dynamic principles in theory and therapy. They became disillusioned with that approach and came, over time, to focus on their patients' conscious beliefs. Both ascribed to an $\mathrm{ABC}$ model, which states that it is not just what happens to someone at point $\mathrm{A}$ (the antecedent events) that determines how the person feels and what he or she does at point $\mathrm{C}$ (the affective and behavioral consequences) but that it also matters how the person interprets those events at point B (the person's beliefs). For example, a man who loses a relationship and is convinced that he was left because he is unlovable is more likely to feel depressed and fail to pursue further relationships than one who considers his loss a consequence of bad luck or the product of mistakes that he will not repeat the next time around.

Both theorists work with patients to actively examine their beliefs to be sure that they are not making situations worse than they necessarily are. Ellis typically adopts a more philosophical approach based on reason and persuasion, whereas Beck operates more like a scientist, treating his patients' beliefs as hypotheses that can be tested and encouraging his patients to use their own behavior to test the accuracy of their beliefs.

These approaches focus on the role of information processing in determining subsequent affect and behavior. Beck (1976) for example, has argued that distinctive errors in thinking can be found in each of the major types of psychopathology. For example, depression typically involves negative views of the self and the future. Efforts to produce change involve having the patient first monitor fluctuations in mood and relate those changes to the ongoing flow of automatic thoughts, subsequently using one's own behavior to test the accuracy of these beliefs. For example, a depressed patient who believes that he or she is incompetent will be asked to provide an example of something he or she should be able to do but cannot. The patient is then invited to list the steps that anyone else would have to do to carry out the task. The patient is then encouraged to carry out those steps just to determine whether he or she is as incompetent as he or she believes (typically, the patient is not).

Applying the above approach to an older adult patient with hearing loss, a depressed patient who believes that he is incompetent to carry out a certain task will be asked to list the steps that anyone with normal hearing would have done to carry out the task, then the patient is encouraged to carry out the steps with hearing aid being fitted.

\subsection{The Therapeutic Procedure}

Cognitive therapy is highly structured in its approach. The initial session or sessions deal with assessment of the problem, development of a collaborative relationship, and case conceptualization. As therapy progresses, a guided discovery approach is used to help clients learn about their inaccurate thinking. Other important aspects of the therapeutic process are methods to identify automatic thoughts and the assignment of homework, which is done throughout therapy. As clients reach their goals, termination is planned and clients work on how they will use what they have learned when therapy has stopped. As therapeutic work progresses, clients move from developing insight into their beliefs to moving toward change. Particularly with difficult and complex problems, insight into the development of negative cognitive schemas is important. Guided discovery, sometimes called Socratic dialogue, guided discovery helps clients change maladaptive beliefs and assumptions. The therapist guides the client in discovering new ways of thinking and behaving by asking a series of questions that make use of existing information to challenge beliefs.

\subsection{Homework}

Much work in cognitive therapy takes place between sessions so that skills can be applied to real-life settings, not just the office (Beck and Tompkins, 2007). Specific assignments are given to help the client collect data, test cognitive and behavior changes, and work on material developed in previous sessions. If the client does not complete the homework, this fact can be useful in examining problems in the relationship between client and therapist or dysfunctional beliefs about doing homework assignments (Beck, 2005). Generally, homework assignments are discussed and new ones developed in each session.

\subsection{Session Format}

Although therapists may have their own format that they adapt for different client problems, there are certain topics to be dealt with in the therapy session (Beck, 1995). The therapist checks on the client's mood and how he is feeling. Usually, the therapist and client agree on an agenda for the therapy session based, in part, on a review of events of the past week and on pressing problems that may have emerged. Also, the therapist asks for feedback about the previous session 
and concerns or problems that the client may have about issues that have occurred since the last meeting. The therapist and client review homework and collaborate to see how the client could get more out of it. Usually, the major focus of the session is on the concerns the client raised at the beginning of the therapy hour. Having dealt with specific items, new homework is assigned relevant to the client's chief concerns. Feedback from the client about the session is an important element of the collaborative relationship between therapist and client.

\subsection{Termination}

Termination may be planned as early as the first session. Throughout treatment, therapists encourage patients to monitor their thoughts or behaviors, report them, and measure progress toward their goals. In the termination phase, the therapist and client discuss how the client can do this without the therapist. Essentially, clients become their own therapists. Just as clients may have had difficulties in accomplishing tasks and may have relapsed into old thought patterns or behaviors, they work on how to deal with similar issues and events after therapy has ended. Commonly, the frequency of therapy sessions reduces and client and therapist may meet every 2 weeks or once a month. Although issues occur in therapy that may require changes in the therapeutic process described here, the specificity of the therapeutic approach, the emphasis on thoughts, and the use of homework are typical. Throughout the process of therapy, a number of strategies are used to bring about changes in thoughts, behaviors, and feelings (Richard, 2012).

\subsection{Therapeutic Techniques}

A wide variety of cognitive techniques are used in helping clients achieve their goals. Some of the techniques focus on eliciting and challenging automatic thoughts, others on maladaptive assumptions or ineffective cognitive schemas. The general approach in cognitive therapy is not to interpret automatic thoughts or irrational beliefs, but to examine them through either experimentation or logical analysis. An example of an experiment would be to ask a client who feels that no one will pay attention to her to initiate a conversation with two acquaintances and observe how they attend or fail to attend to her. An example of questioning a client's logic would be, when the client says "I can never do anything right," to ask "Have you done anything right today?" Cognitive therapists also use techniques to help clients with feelings and behaviors (Richard, 2012).

The following techniques are identified by Richard (2012):

\subsection{Understanding Idiosyncratic Meaning}

Different words can have different meanings for people, depending on their automatic thoughts and cognitive schemas. Often it is not enough for therapists to assume that they know what the client means by certain words. For example, depressed people are often likely to use vague words such as upset, loser, depressed, or suicidal. Questioning the client helps both therapist and client to understand the client's thinking process.

\subsection{Challenging Absolutes}

Clients often present their distress through making extreme statements such as "Everyone at work is smarter than I am." Such statements use words like everyone, always, never, no one, and all the time. Often it is helpful for the therapist to question or challenge the absolute statement so that the client can present it more accurately.

\subsection{Reattribution}

Clients may attribute responsibility for situations or events to themselves when they have little responsibility for the event. By placing blame on themselves, clients can feel more guilty or depressed. Using the technique of reattribution, therapists help clients fairly distribute responsibility for an event.

\subsection{Labeling of Distortions}

Previously, several cognitive distortions such as all-or-nothing thinking, overgeneralization, and selective abstraction were described. Labeling such distortions can be helpful to clients in categorizing automatic thoughts that interfere with their reasoning. For example, a client who believes that her mother always criticizes her might be asked to question whether this is a distortion and whether she is "overgeneralizing" about her mother's behavior.

\subsection{Decatastrophizing}

Clients may be very afraid of an outcome that is unlikely to happen. A technique that often works with this fear is the "what-if" technique. It is particularly appropriate when clients overreact to a possible outcome.

\subsection{Challenging All-or-Nothing Thinking}

Sometimes clients describe things as all or nothing or as all black or all white. The therapist uses a process called scaling, which turns a dichotomy into a continuum.

\subsection{Listing Advantages and Disadvantages}

Sometimes it is helpful for patients to write down the advantages and disadvantages of their particular beliefs or behaviors. This approach is somewhat similar to scaling, as listing the advantages and disadvantages of a belief helps individuals move away from an all-or-none position. 


\subsection{Cognitive Rehearsal}

Imagination in dealing with upcoming events can be helpful. The cognitive rehearsal can be done for an individual with hearing that plans to go for an interview and imagine himself having a successful interview despite having a hearing loss.

Other useful cognitive strategies follow a similar pattern. They question the client's cognitive schemas and automatic thoughts. In addition to cognitive techniques, cognitive therapists may use behavioral techniques such as activity scheduling, behavioral rehearsal, social-skills training, bibliotherapy, assertiveness training, and relaxation training. In the practice of psychotherapy, many of these techniques are used at different times in the therapeutic process to bring about change in cognitions, feelings, and behavior (Richard, 2012).

\section{Effect of Psychotherapy among Client with Hearing Impairment}

Competent mental health counselors managing clients with hearing loss help to focus on the clients' strengths and assets. Strengths-based counseling always focuses on capability, not disability. Individuals with hearing loss learn to reject society's challenges to handicap them through limitations, restrictions, and discrimination (Sussman andBrauer, 1999). Wellness models and positive psychology tactics help to objectify client growth and adjustment, thus promoting competency and potential and enhancing quality of life.

Fengler (1986) explored four schools of psychotherapeutic thinking and potential for contributing to psychotherapeutic work with hearing impaired clients. The aspect of "communication channel" is selected out from systems theory; from psychoanalysis, the concepts of therapeutic contract and transference appear significant; Humanistic Psychology, with its influences concerning extraverbal communication and verbalization of feelings, has opened major routes of right of entry to the hearing impaired individual; the broadest range of concepts and intervention strategies is presented by behavioural therapy. Behavioural approaches--cognitive conditioning, self-control techniques, thoughtstopping, cognitive re-structuring--may be of greatest use in working with deaf clients.

\section{Conclusion}

Cognitive and cognitive-behavioral interventions appear to be effective as other competing alternatives (including medications) and quite possibly more enduring. There are consistent indications that cognitive-behavioral therapy produces long-lasting change that reduces the likelihood that symptoms will return after the treatment ends. The evidence is mixed with respect to substance abuse, marital distress and childhood conduct disorder. Cognitive and cognitivebehavioral interventions are typically not thought to be particularly effective in patients who have formal thought disorder, although recent studies suggest that such interventions may reduce delusional thinking in psychotic patients who receive neuroleptic drugs (Ebert, Loosen, Nurcombe and Leckman, 2008).

Patients often suffer from hearing loss has psychosocial difficulties and psychiatric comorbidity, psychological assessment is vital in the management of patients with hearing loss who has psychosocial difficulties and psychiatric comorbidity. There is evidence that cognitive behavioral therapy can be effective for easing the distress caused by hearing loss. We need more work to reach the level of success obtained for problems such as anxiety and depression associated with hearing loss.

\section{References}

i. Abby McCormackand Heather Fortnum. (2013). Why do people fitted with hearing aids not wear them? Int J Audiol.; 52(5): 360-368 doi: 10.3109/ 14992027.2013.769066

ii. Andersson, G. (2002). Psychological aspects of tinnitus and the application of cognitive-behavioral therapy. Clinical Psychology Review, 22, 977-990.

iii. Abrams, T.E., Barnett, M.J., Hoth, A., Schultz, S. and Kaboli, P.J. (2006). The relationship between hearing impairment and depression in older veterans. Journal of the American Geriatrics Society, 54(9), pp.1475-1477.

iv. Appollonio I, Carabellese C, Frattola L, Trabuc-chi M. (1996) Effects of sensory aids on the quality of life and mortality of elderly people: a multivariate analysis. Age Ageing; 25:89-96.

v. Beck A.T. (1976). Cognitive Therapy and Emotional Disorders. Madison CT: International Universities Press.

vi. Beck, A. T., Kovacs, M. and Weissman, A. (1979). Assessment of suicidal intention: The Scale for Suicidal Ideation. Journal of Consulting and Clinical Psychology, 47, 343-352.

vii. Beck, A. T., Rush, A. J., Shaw, B. F., and Emery, G. (1979). Cognitive therapy of depression. New York: Guilford.

viii. Beck, A. T., Ward, C. H., Mendelson, M., Mock, J. E., and Erbaugh, J. K. (1961). An inventory for measuring depression. Archives of General Psychiatry, 4, 561-571.

ix. Beck, A.T. (1967). Depression: Clinical, experimental, and theoretical aspects. New York: Hoeber.

x. Beck, A.T. (1991). Cognitive therapy: A 30-year retrospective. American Psychologist, 46, 368-375.

xi. Beck, A.T. (2001). Biography of Aaron T. Beck, M.D. The Corsini Encyclopedia of Psychology and Behavioral Science (3rd ed., pp. 177-178). New York: Wiley

xii. Beck, A.T., and Weishaar, M. (1989). Cognitive therapy. In Freeman, A., Simon, K.M., Beutler, L.E., and Arkowitz, H. (Eds.), Comprehensive handbook of cognitive therapy, pp. 21-36. New York: Plenum.

xiii. Beck, A.T., Freeman, A., Davis, D.D. and Associates. (2004). Cognitive therapy of personality disorders (2nd ed.). New York: Guilford.

xiv. Beck,J. S. (1995). Cognitive therapy: Basics and beyond. New York: Guilford.

xv. Beck, J. S. (2005). Cognitive therapy for challenging problems: What to do when the basics don't work. New York: Guilford. 
xvi. Beck, J. S., and Tompkins, M. A. (2007). Cognitive therapy. In N. Kazantzis and L. L'Abate (Eds.). Handbook of homework assignments in psychotherapy: Research, practice, prevention (pp. 51-63). New York: Springer.

xvii. Blankstein, K. R. and Segal, Z. V. (2001). Cognitive assessment: Issues and methods. In K. S. Dobson (Ed.), Handbook of cognitive behavioral therapies (2nd ed., pp. 40-85). New York: Guilford.

xviii. Boness, C L. (2016). Treatment of deaf clients: Ethical considerations for professionals in psychology. Ethics \& behavior, 26, 562-585.

xix. Brooks D.N. (1985) Factors relating to the under-use of postaural hearing aids. Br J Audiol.; 19:211-217.

xx. Chien W, Lin F.R. (2012). Prevalence of hearing-aid use among older adults in the United States. Arch Intern Med.; 172:292-293.

xxi. Cohen-Mansfield J., Taylor J.W. (2004). Hearing aid use in nursing homes, Part 2: Barriers to effective utilization of hearing aids. J Am Med Direct Assoc.; 5:289-29.

xxii. Cozolino , L. ( 2017). The neuroscience of psychotherapy: Healing the social brain, WW Norton \& Company

xxiii. Davis W.E. (2001). Proportional frequency compression in hearing instruments. The Hearing Review. 2001 Feb;34-42

xxiv. DeRubeis, R. J., Tang, T. Z. and Beck, A. T. (2001). Cognitive therapy. In K. S. Dobson (Ed.), Handbook of cognitivebehavioral therapies. 2nd ed., pp. 349-392. New York: Guilford.

xxv. Dobie, R. A. (1999). A review of randomized clinical trials in tinnitus. The Laryngoscope, 109, 1202-1211.

xxvi. Ebert, M.H., Loosen, P.T., Nurcombe, B. and Leckman, J.F. (Eds.), (2008). Current diagnosis and treatment: Psychiatry. 2nd Ed, McGraw -Hill pp 144-'146.

xxvii. Edelwich, J., \&Arre, P. (1987). Reality therapy as an intervention for deaf adolescents involved in alcohol and drug use and abuse. In G. B. Anderson \& D. Watson (Eds.), Innovations in the habilitation and rehabilitation of deaf adolescents (pp. 344-349). Little Rock, AR: American Deafness and Rehabilitation Association.

xxviii. Ellis A. (1962). Reason and Emotion in Psychotherapy. New York: Lyle Stuart.

xxix. Fengler J 1986. Psychotherapy of patients with hearing impairment. Die Rehabilitation, 25, 166-172.

xxx. Freeman, A. (1987). Cognitive therapy: An overview. In Freeman, A. and Greenwood, V. (Eds.), Cognitive therapy: Applications in psychiatric and medical settings, pp. 19-35. New York: Human Science Press.

xxxi. Freeman, A., Pretzer, J., Fleming, B., and Simon, K. M. (1990). Clinical applications of cognitive therapy. New York: Plenum.

xxxii. Garberoglio, C. L., Dickson, D., Cawthon, S., Bond. M. (2015). Bridging the communication divide: CMC and deaf individuals' literacy skills.

xxxiii. Gopinath B, Wang J.J, Schneider J, Burlutsky G, Snowdon J, McMahon CM, Leeder SR and Mitchell P. (2009). Depressive symptoms in older adults with hearing impairments: the Blue Mountains Study. J Am Geriatr Soc. 2009;57:1306-1308. doi: 10.1111/j.1532-5415.2009.02317.x

xxxiv. Goulios H., Patuzzi R.B. (2008). Audiology education and practice from an international perspective. Int J Audiol;47:647-664.

xxxv. Gutman, V. (Ed.). (2002). Ethics in mental health and deafness. Washington, DC: Gallaudet University Press.

xxxvi. Hall, M.L. and Bavelier, D.(2010). 30 Working memory, deafness, and sign language. The Oxford Handbook of Deaf Studies, Language, and Education, eds M. Marksharks and PE Spencer (New York, NY: Oxford University Press), 2, pp.458-475.

xxxvii. Hallam, R. (1984). Psychological aspects of tinnitus. Contributions to Medical Psychology. S. Rachman

xxxviii. Hammill, D.D. and Pearson, N.(2017). Comprehensive test of nonverbal intelligence. In Handbook of Nonverbal Assessment (pp. 167-184). Springer, Cham.

xxxix. Hartley D., Rochtchina E., Newall P., Golding M. Mitchell P. (2010). Use of hearing aids and assistive listening devices in an older Australian population. J Am Acad Audiol. ; 21:642-653.

xl. Hawton, K.E., Salkovskis, P.M., Kirk, J.E. and Clark, D.M.(1989). Cognitive behaviour therapy for psychiatric problems: A practical guide. Oxford University Press.

xli. Hill-Briggs, F., Dial, J.G., Morere, D.A. and Joyce, A. (2007). Neuropsychological assessment of persons with physical disability, visual impairment or blindness, and hearing impairment or deafness. Archives of clinical neuropsychology, 22(3), pp.389-404.

xlii. Hogan A, O'Loughlin K, Miller P, Kendig H. (2009). The health impact of a hearing disability on older people in Australia. J Aging Health. ;21(8):1098-1111.

xliii. Hougaard S., Ruf S. EuroT. (2011). A consumer survey about hearing aids in Germany, France, and the UK. Hearing Review.

xliv. Kochkin S. MarkeTrak VIII. (2009) 25-year trends in the hearing health market. Hearing Review. Oct;:12-31.

xlv. Kochkin S. MarkeTrak III. (1993). Why 20 million in US don't use hearing aids for their hearing loss? The Hearing Journal; 46:28-31.

xlvi. Li, C.- M., Zhang, x., Hoffman, h. J., Cotch, M. F., Themann, C. L. and Wilson, M. R. (2014). Hearing impairment associated with depression in us adults, national health and nutrition examination survey 2005-2010. Jama otolaryngology-head \& neck surgery, 140, 293-302.

xlvii. Leybaert, J. and Alegria, J.(2003). The Role of Cued Speech in Language Development. Oxford handbook of deaf studies, language, and education, p.261.

xlviii. Izydorczyk, B.(2011). Application of Psychodrama and Object Relations Psychotherapy-An Integrated Approach to the Treatment of Bulimia Nervosa Based on Selected Elements of the Theory and the Author's Own Experience. In New Insights into the Prevention and Treatment of Bulimia Nervosa. InTech. 
xlix. Mischel, W. (2013). Personality and assessment. Psychology Press.

1. World Health Organization. (2017). Depression and other common mental disorders: global health estimates.

li. Perez E., Edmonds B.A. (2012). A systematic review of studies measuring and reporting hearing-aid usage in older adults since 1999: A descriptive summary of measurement tools. PLoS ONE. 2012;7:e31831.

lii. Pollard Jr, R.Q., Betts, W.R., Carroll, J.K., Waxmonsky, J.A., Barnett, S., Pickler, L.L. and Kellar-Guenther, Y. (2014). Integrating primary care and behavioral health with four special populations: Children with special needs, people with serious mental illness, refugees, and deaf people. American Psychologist, 69(4), p.377.

liii. Raval, H. (1996). A systemic perspective on working with interpreters. Clinical child psychology and psychiatry, $1(1)$, pp.29-43.

liv. Richard S. S. (2012). Theories of Psychotherapy and Counseling; Concept and Cases. 5th Edition, CENGAGE Learning.

lv. Romero, E.M.G. (2016). Deaf university students' knowledge of the Miranda warnings. Gallaudet University.

lvi. Sorri M., Luotonen M., Laitakari K. (1984). Use and non-use of hearing aids. Br J Audiol.;18:169-172.

lvii. Staehelin K., Bertoli S., Probst R., Schindler C., Dratva J. and Stutz E. Z. (2011). Gender and hearing aids: Patterns of use and determinants of nonregular use. Ear Hear. 2011;32:e26-e37.

lviii. Sussman, A. E and Brauer, B. A. (1999). On being a psychotherapist with deaf clients. In I. W. Leigh (Ed.), Psychotherapy with deaf clients from diverse groups (pp. 3-22). Washington, DC: Gallaudet University Press.

lix. Tribe, R. and Lane, P.(2009). Working with interpreters across language and culture in mental health. Journal of mental health, 18(3), pp.233-241

lx. Upfold L.J. and Wilson D.A. (1980) Hearing-aid distribution and use in Australia. The Australian Bureau of Statistics 1978 Survey. Aust J Audiol.; 2:31-36.

lxi. World Health Organization (2006) Deafness and hearing impairment. Fact sheet No. 300. http:/ / www.who.int/ mediacentre/ factsheets/ fs300/ en/ index.html

lxii. Weissman, A. (1979).The Dysfunctional Attitudes Scale. Philadelphia: Center for Cognitive comorbidity. New Therapy.

lxiii. Whisman, M. A. (Ed.). (2008). Adapting cognitive therapy for depression: Managing complexity and York: Guilford Press.

lxiv. Young, J. E., and Brown, G. (1999). Young Schema Questionnaire. In J. E. Young (Ed.), Cognitive therapy for personality disorders: A schema-focused approach (rev. ed., pp. 63-76). Sarasota, FL: Professional Resources Press. 